\title{
Ground-based lidar for atmospheric boundary layer ozone measurements
}

\author{
Shi Kuang, ${ }^{1, *}$ Michael J. Newchurch, ${ }^{1}$ John Burris, ${ }^{2}$ and Xiong Liu ${ }^{3}$ \\ ${ }^{1}$ Atmospheric Science Department, University of Alabama in Huntsville, 320 Sparkman Dr., \\ Huntsville, Alabama 35805, USA \\ ${ }^{2}$ NASA-Goddard Space Flight Center, Code 694, Greenbelt, Maryland 20771, USA \\ ${ }^{3}$ Atomic and Molecular Physics Division, Harvard Smithsonian Center for Astrophysics, \\ Cambridge, Massachusetts 02138, USA \\ ${ }^{*}$ Corresponding author: kuang@ nsstc.uah.edu
}

Received 4 February 2013; revised 15 April 2013; accepted 24 April 2013;

posted 24 April 2013 (Doc. ID 184786); published 16 May 2013

\begin{abstract}
Ground-based lidars are suitable for long-term ozone monitoring as a complement to satellite and ozonesonde measurements. However, current ground-based lidars are unable to consistently measure ozone below $500 \mathrm{~m}$ above ground level (AGL) due to both engineering issues and high retrieval sensitivity to various measurement errors. In this paper, we present our instrument design, retrieval techniques, and preliminary results that focus on the high-temporal profiling of ozone within the atmospheric boundary layer (ABL) achieved by the addition of an inexpensive and compact mini-receiver to the previous system. For the first time, to the best of our knowledge, the lowest, consistently achievable observation height has been extended down to $125 \mathrm{~m}$ AGL for a ground-based ozone lidar system. Both the analysis and preliminary measurements demonstrate that this lidar measures ozone with a precision generally better than $\pm 10 \%$ at a temporal resolution of $10 \mathrm{~min}$ and a vertical resolution from $150 \mathrm{~m}$ at the bottom of the ABL to $550 \mathrm{~m}$ at the top. A measurement example from summertime shows that inhomogeneous ozone aloft was affected by both surface emissions and the evolution of ABL structures. (C) 2013 Optical Society of America

OCIS codes: $\quad$ (280.1120) Air pollution monitoring; (010.1280) Atmospheric composition; (280.1910)

DIAL, differential absorption lidar; (010.3640) Lidar; (010.4950) Ozone.

http://dx.doi.org/10.1364/AO.52.003557
\end{abstract}

\section{Introduction}

Vertical profiling of atmospheric boundary layer $(\mathrm{ABL})$ ozone is important for understanding the interaction between surface and upper-altitude air, validating satellite retrievals, and evaluating photochemical or air-quality models. Anthropogenic pollution generally originates at ground level and subsequently impacts the downwind surface air quality through transport over various spatiotemporal scales [1-3]. Surface ozone is coupled with the upper-air ozone, although these regions have distinct diurnal variations.

$1559-128 \mathrm{X} / 13 / 153557-10 \$ 15.00 / 0$

(C) 2013 Optical Society of America
As a complement to satellite and ozonesonde measurements, lidar profiling in the ABL has been previously carried out using both airborne [4-6] and ground-based systems [7-9]. These lidars generally retrieve ozone profiles with a vertical resolution of hundreds of meters and an integration time of minutes. These efforts have significantly added to our understanding of tropospheric chemistry and dynamics. However, the quantity of these ozone lidar data has been limited and unable to satisfy our requirement for high-resolution data, especially within the ABL where both the vertical resolution of the satellite retrieval and the temporal resolution of the ozonesonde are coarse.

Although airborne lidars retrieve near-surface ozone over large spatial regions, they have limited 
precision near the surface, which is at their far range. Moreover, airborne lidars require significant operational costs that limit their deployment. To our knowledge, except for lidars operating in a horizontal scanning configuration [10], the lower limit for ozone retrievals by ground-based lidars is generally $500 \mathrm{~m}$ above ground level (AGL) due to several difficulties. First, near-surface ozone measurement requires rapid overlap of the receiver field of view (FOV) and laser beam divergence. This overlap can significantly increase the near-range signal intensity that saturates the detector and results in nonlinear signals [11]. The conventional chopper or gating system response is not rapid enough to protect the system. Second, the large dynamic range, due to strong Rayleigh and aerosol scattering, requires multiple detectors to cover the entire ABL $(<\sim 2 \mathrm{~km})$. This adds to the complexity of the detector design and the retrieval algorithm. Third, synchronization of the timing between on- and off-line wavelengths is critical because of the rapidly decaying backscatter signal. Small timing offsets will result in large ozone retrieval errors. Fourth, the uncertainty in the lower ABL ozone lidar retrieval caused by aerosol interference can be high due to differential aerosol backscattering, and the unknown Ångström exponent and lidar ratio.

In this article, we point out the challenges for ozone lidar measurement within the ABL, particularly near the surface, and present our design solutions and retrieval methodology for overcoming these difficulties. Then, we show an example of our ozone measurements by focusing on the ABL. Finally, we examine the resulting retrieval precision.

\section{Instrument}

Our tropospheric ozone differential absorption lidar (DIAL) is located on the fourth floor of the National Space Science \& Technology Center (NSSTC) on the campus of the University of Alabama in Huntsville (UAHuntsville) at an elevation of $\sim 206 \mathrm{~m}$ above sea level. This system currently retrieves ozone between 0.125 and $\sim 12 \mathrm{~km}$ AGL using three receivers $(2.5,10$, and $40 \mathrm{~cm})$ and a wavelength pair of 285 and $291 \mathrm{~nm}$.

\section{A. Laser Transmitter}

Table 1 presents the characteristics of the UAHuntsville ozone lidar. The laser transmitter consists of two wavelength-tunable dye lasers, pumped by two separate frequency-doubled $\mathrm{Nd}$ :YAG lasers at $532 \mathrm{~nm}$. The $30 \mathrm{~Hz}$ pump lasers are triggered by an external pulse generator with a $16.7 \mathrm{~ms}$ separation between the alternate pulses. The dye lasers are frequency doubled to generate two ultraviolet (UV) laser beams at 285 and $291 \mathrm{~nm}$ with energy of 5-7 $\mathrm{mJ} \cdot$ pulse $^{-1}$ and pulse length of $\sim 7 \mathrm{~ns}$. The outgoing beams have near-field diameters of $\sim 6 \mathrm{~mm}$ and divergences of less than $1 \mathrm{mrad}$. Compared with the previous system [12], the pump lasers were upgraded in 2010 and the resulting increase in UV energies raised the upper observation limit to $\sim 12 \mathrm{~km}$.

Table 1. Characteristics of the UAHuntsville Ozone Lidar

\begin{tabular}{|c|c|c|c|c|}
\hline Transmitter & \multicolumn{4}{|c|}{ Specification } \\
\hline $\begin{array}{l}\text { Pump lasers } \\
\text { Dye } \\
\text { Emitted UV lasers }\end{array}$ & \multicolumn{4}{|c|}{$\begin{array}{l}\mathrm{Nd}: \mathrm{YAG}, 30 \mathrm{~Hz} \text { repetition rate, } 150 \mathrm{~mJ} \cdot \text { pulse }^{-1} \text { at } 532 \mathrm{~nm} \\
\text { Mixture of rhodamine } 590 \text { and } 610 \\
\mathrm{se}^{-1} \text { at } 285 \mathrm{~nm}, 5-6 \mathrm{~mJ} \cdot \text { pulse }^{-1} \text { at } 291 \mathrm{~nm} ; 0.6 \mathrm{~cm} \text { near-field beam diameter, } \\
7 \mathrm{~ns} \text { pulse length and divergence }<1 \mathrm{mrad} \text { for both lasers }\end{array}$} \\
\hline Receiver & Channel 1 & Channel 2 & Channel 3 & Channel 4 \\
\hline Diameter $(\mathrm{cm})$ & 2.5 & 10 & 10 & 40 \\
\hline Focal length (m) & 0.1 & 2.3 & 2.3 & 4.5 \\
\hline Separation from the laser beams $(\mathrm{cm})$ & 10 & 20 & 20 & 50 \\
\hline FOV (mrad) & 10 & 4.3 & 4.3 & 1.5 \\
\hline $\begin{array}{l}\text { Full overlap height (meter above } \\
\text { the laboratory) }\end{array}$ & 20 & 90 & 90 & 1200 \\
\hline Light split percentage $(\%)$ & 100 & 10 & 90 & 100 \\
\hline Solar blind filter & \multicolumn{4}{|c|}{$\begin{array}{l}\text { Center wavelength at } 286.4 \mathrm{~nm} \text { with a } 11 \mathrm{~nm} \text { FWHM; } 35 \% \\
\text { transmittance at } 285 \mathrm{~nm} \text { and } 20 \% \text { transmittance at } 291 \mathrm{~nm}\end{array}$} \\
\hline Neutral density filter transmittance & $10 \%$ & $10 \%$ & $32 \%$ & NA \\
\hline PMT type & Hamamatsu R9880U & Hamamatsu R7400U & Hamamatsu R7400U & Electron Tube9831QA \\
\hline Gated PMT delay $(\mu \mathrm{s})$ & 0 & 0 & 1 & $>10$ \\
\hline Measurable height range $(\mathrm{km})$ & $0.1-1$ & $0.4-1.5$ & $1-4$ & $3-12$ \\
\hline Signal processing & Channel 1 & Channel 2 & Channel 3 & Channel 4 \\
\hline $\begin{array}{l}\text { Photon counting } \\
\text { Analog }\end{array}$ & \multicolumn{4}{|c|}{$\begin{array}{l}250 \mathrm{MHz} \text { maximum counting rate } \\
12 \text { bit and } 40 \mathrm{MHz} \text { analog-to-digital converter }\end{array}$} \\
\hline Fundamental range resolution $(\mathrm{m})$ & 3.75 & 3.75 & 3.75 & 3.75 \\
\hline $\begin{array}{l}\text { Degraded range resolution } \\
\text { due to average }(\mathrm{m})^{a}\end{array}$ & 22.5 & 45 & 75 & 150 \\
\hline
\end{tabular}


The selection of on- and off-line wavelengths at 285 and $291 \mathrm{~nm}$ is a compromise between minimizing the solar background, reducing the impact of the aerosol interference, and maximizing the range limit. Although the uncertainties in the DIAL retrieval due to aerosols have a complicated relationship with the wavelengths, their separation, and the local aerosol conditions, wavelengths between 285 and $300 \mathrm{~nm}$ have been previously shown [13-16] to retrieve ozone with acceptable errors if the aerosol correction is

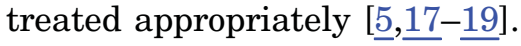

\section{B. Lidar Receiver}

The receiving system consists of three receivers and four photomultipliers (PMTs) as shown in Fig. 1 and listed in Table 1 . The 2.5, 10, and $40 \mathrm{~cm}$ receivers fully overlap both laser beams at 20, 90, and $1200 \mathrm{~m}$, respectively, above the laboratory height. The lidar receiver configuration is similar to that reported by Kuang et al. [12] except for the addition of a $2.5 \mathrm{~cm}$ mini-receiver and a beamsplitter in the $10 \mathrm{~cm}$ receiver. In 2008 , a 10\%-90\% beamsplitter was integrated into the $10 \mathrm{~cm}$ receiver and extended the observations down to $500 \mathrm{~m}$ AGL using the $10 \%$ channel $[20,21]$. Modifying a design used in a previous National Aeronautics and Space Administration (NASA) airborne lidar campaign [22], a $2.5 \mathrm{~cm}$ diameter receiver was recently added to lower the lidar's minimum observable altitude. This approach, using four PMT (or altitude) channels, provides necessary dynamic range to cover both the ABL and the free troposphere under expected atmospheric

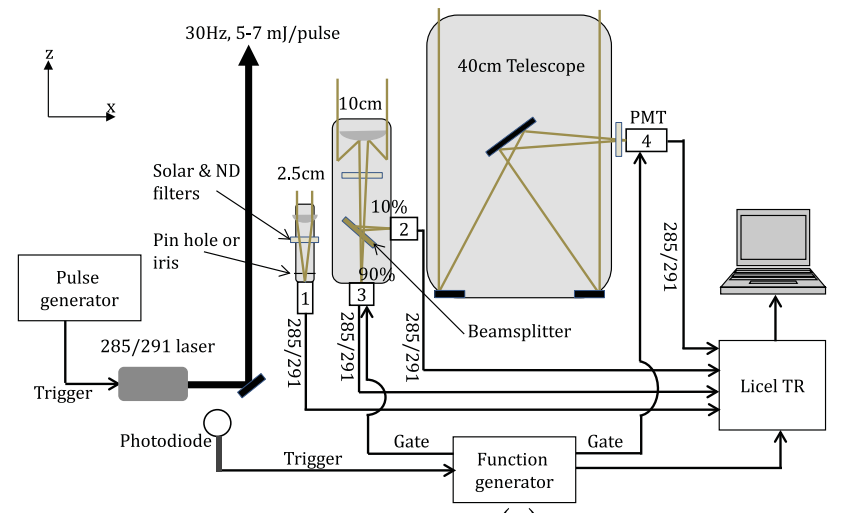

(a)

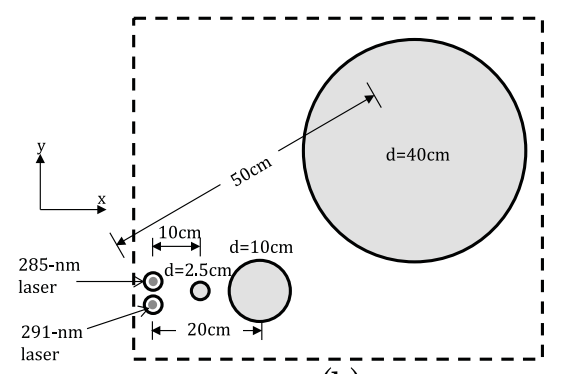

(b)

Fig. 1. Configuration schematic for the UAHuntsville ozone lidar in (a) its vertical cross section and (b) its horizontal cross section. conditions. For each laser, a photodiode detects the outgoing laser pulse and triggers a function generator to control the timing sequence for both the Licel (Licel GmbH, Germany) transient recorder (TR, model 40-80) and the gating system. The PMTs for the two high-altitude channels (channels 3 and 4) are gated typically for the first 1 and $10 \mu \mathrm{s}$, respectively, to avoid saturation. Although this paper discusses only the ABL ozone measurement, we still present the parameters for all of the channels in Table 1 for convenient comparison.

As shown in Fig. 2, the mini-receiver consists of an adjustable focusing element holding a $10 \mathrm{~cm}$ focal length plano-convex lens that facilitates the optimization of the distance between the lens and the PMT. An adjustable iris is inserted between the $10 \mathrm{~cm}$ lens tube and PMT to control the receiver's FOV. The iris can be replaced by a suitably sized pin hole after the FOV is experimentally determined. Currently, the FOV is set to $10 \mathrm{mrad}$ to ensure that the receiver and laser are fully overlapped at $\sim 20 \mathrm{~m}$. At the lower part of the mini-receiver, a Licel module incorporating a compact Hamamatsu R9880U PMT detects backscattered photons. Although the photocathode area size of this R9880U PMT is only $8 \mathrm{~mm}$, it is sufficient to fully cover the backscattered light that passes through the receiver aperture without a difficult manual alignment. A solar filter is employed for daytime measurements. A $10 \mathrm{~dB}$ neutral density filter is typically added into channel 1 to maintain the linearity of backscatter signals because its PMT is not gated.

\section{Range Registration Offset}

For ozone retrievals, the ranges of the on- and off-line wavelengths should have the same reference height, which is typically the ground. The offset in range registration between the two wavelengths, $r^{*}$ (or $t^{*}=$ $2 r^{*} / c$ accounting for the two-way travel, where $c$ is the light speed), was not emphasized for highaltitude retrievals in previous publications because of the slowly decaying signal and long integration range interval (usually more than $100 \mathrm{~m}$ ). However, minimizing this offset is critical for near-surface measurements.

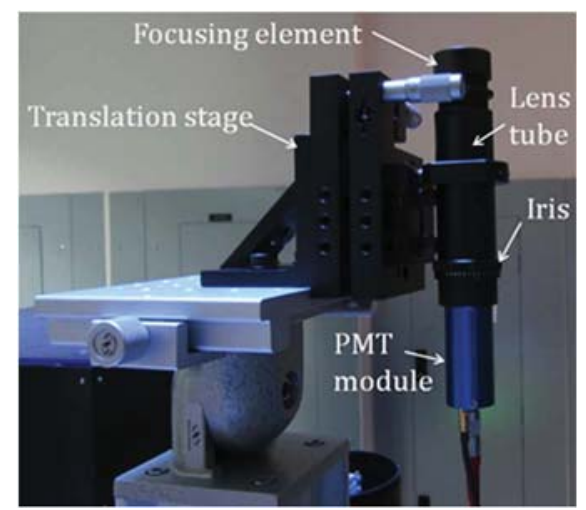

Fig. 2. Design of the $2.5 \mathrm{~cm}$ receiver. 


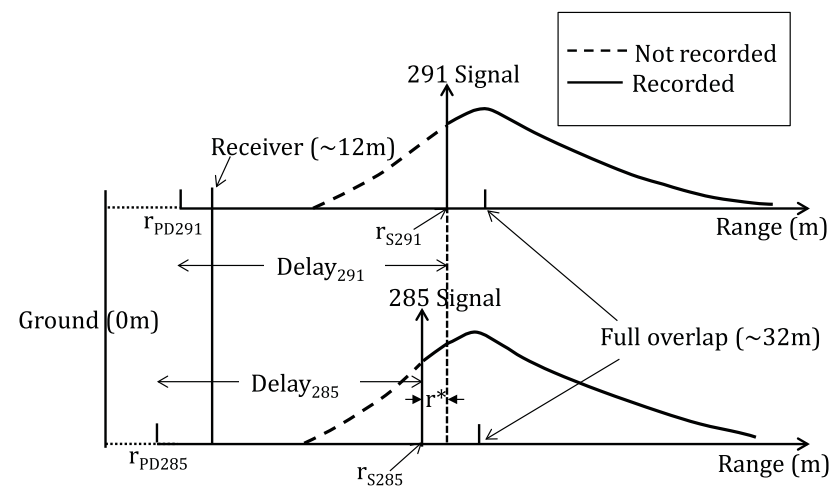

Fig. 3. Timing chart for the $2.5 \mathrm{~cm}$ receiver. $r_{\mathrm{PD}}$ represents the range (or the height AGL) of the photodiode trigger pulse, and $r_{S}$ denotes range at the start of the data recording by the Licel TR, which is a photon counter. Subscripts 285 and 291 represent the two lasers. Receiver is located at approximately $12 \mathrm{~m}$ AGL for both lasers, which is the laboratory height. The solid portions of the signals represent the signals that are recorded by the TR. The dashed portion is not recorded. For accurate DIAL retrieval, $r^{*}$ should be minimized by adjusting Delay 285 and Delay $_{291}$.

Figure 3 presents the schematic timing chart for our $2.5 \mathrm{~cm}$ receiver channel (channel 1 ). The delay (denoted by Delay 285 or Delay 291 for the two lasers) between the photodiode trigger (also refer to Fig. 1) and the start of data recording consists of the time that signals take to traverse the cables [typically the Bayonet Neill-Concelman (BNC) cables] and the internal delay between the different trigger channels of the function generator and, finally, the internal delay in the Licel TR. Because of these delays, the TR misses the dashed portion of the backscattered signals in Fig. 3 . However, further effort to reduce those delays is not necessary because the missed signals are below the full overlap altitude where we are currently unable to obtain reliable retrievals. To minimize $r^{*}$ so that the 285 and $291 \mathrm{~nm}$ signals have the same range registration, we adjust Delay ${ }_{285}$ and Delay $_{291}$ by changing the BNC cable lengths and monitoring both Delay $_{285}$ and Delay 291 using an oscilloscope. The pulse lengths and shapes observed by the photodiode need to be accounted for if they are different for the two UV beams. In practice, if the pulse shapes are difficult to measure, an empirical correction (e.g., tuning cable length based on the calibration using other instruments) may be necessary for the near-range retrievals even after various efforts have been taken for minimizing $r^{*}$.

Figure 4 shows modeling results for errors in the DIAL retrievals due to $r^{*}$ as a function of range by assuming a $1.5 \times 10^{12}$ molecule $\mathrm{cm}^{-3}$ constant ozone profile, no aerosol, and using the 1976 U.S. Standard Atmosphere [23]. The ozone number densities were computed without any filtering or smoothing because no modeled random errors were added onto the simulated signals. When $r^{*}$ is greater than $0.5 \mathrm{~m}$, the retrieval errors become significant $(>10 \%)$ below

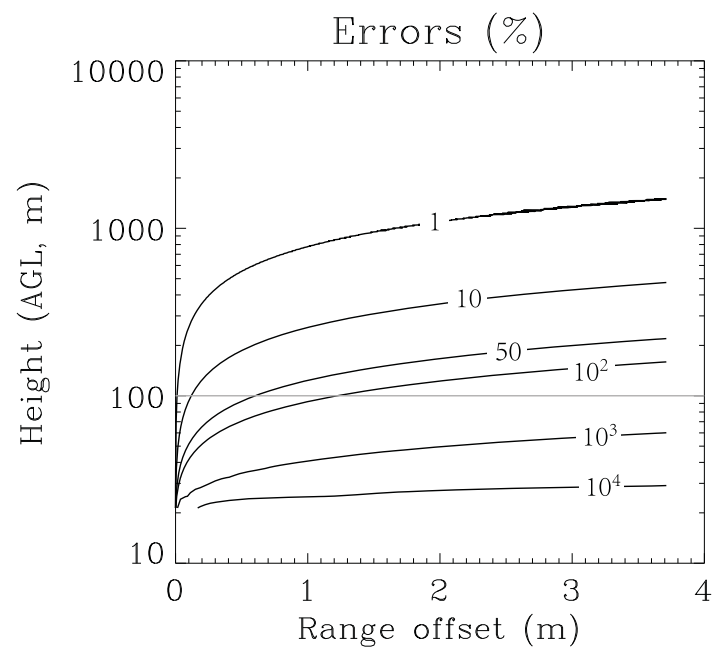

Fig. 4. Modeled percentage errors in the DIAL retrievals due to range registration offsets, $r^{*}$, between on- and off-line wavelength by assuming a $1.5 \times 10^{12}$ molecule $\mathrm{cm}^{-3}$ constant ozone profile, no aerosol, and using the 1976 U.S. Standard Atmosphere [23]. Every $1.5 \mathrm{~m}$ range offset corresponds to a $10 \mathrm{~ns}$ time offset.

$200 \mathrm{~m}$. The retrieval errors are sensitive to $r^{*}$, especially when $r^{*}$ is small, and insensitive to the designated retrieval interval ( $\Delta r$ in DIAL equation). These errors are primarily attributable to the different Rayleigh extinctions at ranges between $r$ and $r+r^{*}$ and decrease quasi-exponentially with range because the Rayleigh extinction decreases exponentially with range.

\section{Data Processing}

To improve measurement precision, several techniques are employed on the raw lidar signal. The temporal integration time is typically set at $10 \mathrm{~min}$. The integrated spatial range intervals are 22.5, 45, and $75 \mathrm{~m}$ for PMT channels 1,2 , and 3 (Fig. 1). The nonparalyzable dead time [24] has been empirically determined to be $\sim 4 \mathrm{~ns}$ and is largely associated with the type of PMT and the counter's discriminator level. Far-range signals, where no laser signal returns are expected, are averaged to give an appropriate background for each wavelength and PMT channel. Although analog signals (12 bit) are conventionally considered to be less reliable than photon counting (PC), they can increase the virtual counting rates and thus improve the dynamic range. The analog and PC signals are merged together at counting rates between 20 and $30 \mathrm{MHz}$ after their offset [25], $\sim 250 \mathrm{~ns}$ for our system, is removed. An exponential function, determined using a least squares fit to data acquired approximately from 100 to $160 \mu \mathrm{s}$, simulates the signal-induced bias (SIB) [26]. The SIB correction is empirical; however, it can significantly impact the precision of the farrange retrievals. Two dominate factors affecting SIB are the PMT type and the backscattered signal intensity. In our measurements, SIB is often easy to characterize in the nighttime data when the solar background is nonexistent. 


\section{DIAL Retrieval}

The DIAL equation can be simplified as [27]

$$
n_{o 3(r)}=\frac{-1}{2 \Delta O_{3(r)}} \frac{d}{d r}\left[\ln \frac{P_{\mathrm{on}(r)}}{P_{\mathrm{off}(r)}}\right]+\Delta n_{o 3(r)},
$$

where $n_{o 3(r)}$ is the ozone number density at range $r$, $\Delta O_{3(r)}$ is the differential ozone absorption cross section, $P_{\text {on }(r)}$ and $P_{\text {off }(r)}$ are the backscattered on- and off-line lidar returns, and $\Delta n_{o 3(r)}$ is the residual ozone term including Rayleigh and aerosol corrections. The first term of the right side of Eq. (1) is often called the signal term.

After processing, the ratios of on- and off-line signals as a function of range are computed. The derivative of the logarithm of the signal ratios can be calculated by either the discrete form or an inner derivative function of certain advanced computer language (e.g., IDL or MATLAB). We choose the latter method because it is easier to deal with the edge effect of the near-ground signal and is more flexible to filter out the random noises with variable widths of the convolution window. Savitzky-Golay (SG) low-pass filters [28] can smooth the data using a polynomial of arbitrary degree and width, and unequal spacing between data points. Therefore, this method can handle well the lowest data point and is particularly suitable for near-ground signal processing. We employ a first-order SG differentiation filter with a second-degree polynomial and variable fitting widths to $\ln P_{\text {on }(r)} / P_{\text {off }(r)}$ smooth. A large width is preferred at far ranges where the signal-tonoise ratios (SNRs) are relatively low. Filtering widths over the same altitude range can also vary with PMT channels, where their detected signal intensities are significantly different.

The effective spatial resolution of the final ozone retrieval $\left(\Delta r_{e}\right)$, which determines the ability to see fine detail in the data, is not equal to, but is associated with the convolution (fitting) window width $\left(L_{S}\right) . \Delta r_{e}$ is always better than $L_{S}$ and worse than the integrated signal interval $(\Delta r) . \Delta r_{e}$ can be defined by $L_{S} / f_{c}$ [29], where $f c$ is the cutoff frequency at a predefined attenuation threshold, typically $-3 \mathrm{~dB}$. The optimum $3 \mathrm{~dB}$ down $f c$ of the SG filter for the second-degree polynomial fitting is close to $2 \mathrm{~Hz}$ [30], theoretically. However, previously reported resolutions in lidar retrievals calculated by various methods [31,32] were lower than the optimum value. We conservatively assume an $f c$ at $1.6 \mathrm{~Hz}$ [33] to estimate the effective resolutions of the DIAL retrievals as a function of range for each channel shown by Fig. 5. Generally, a symmetrical (bins on the left side and right side are equal) SG filter with a half-width of 6 bins is applied on the logarithm of the signal ratios for all channels. In spite of the same number of bins, the filtering widths of the channels still differ because channels 1,2 , and 3 have bin lengths of $22.5,45$, and $75 \mathrm{~m}$, respectively. At the lower-range limit where the data points do not allow for a symmetrical window, a filter with a nonsymmetric width

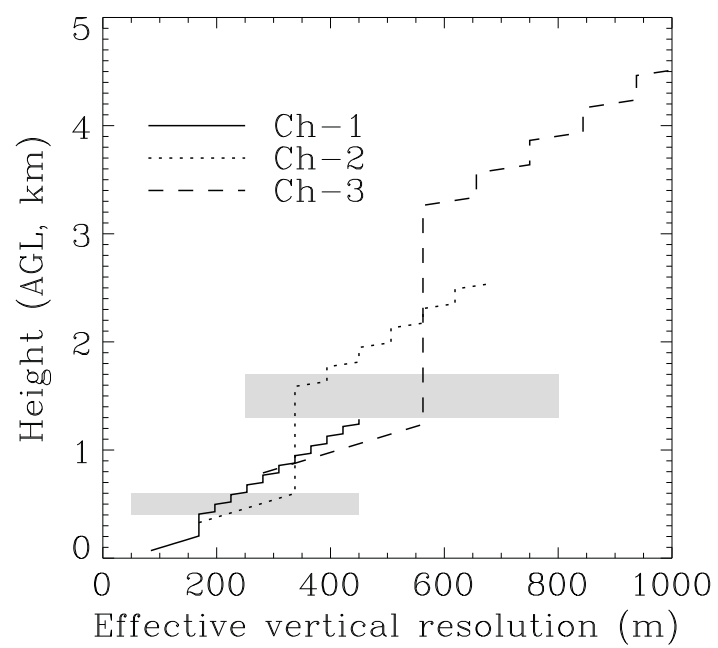

Fig. 5. Estimated effective spatial resolutions of the DIAL retrievals as a function of range for channels 1,2 , and 3 . The step-function-like increase in resolution at the upper range of each channel is due to an increasing filtering width. The gray shaded areas designate the region where the adjacent channels can be joined together.

is employed. Because of the higher uncertainties inherent in using a nonsymmetric filter, especially in the presence of a large ozone gradient condition, the ozone retrievals in the initial 2 or 3 bins are discarded, and the first valid retrieval occurs at $\sim 122 \mathrm{~m}$ AGL (or $\sim 110 \mathrm{~m}$ above laboratory). At the upper range limit a filter with a linearly increasing width is applied due to the low SNRs. In the ABL, the estimated retrieval $\Delta r_{e}$ increases with height from $\sim 150$ to $\sim 550 \mathrm{~m}$. The ozone retrievals of adjacent channels can be joined together based on their statistical uncertainties [12] in the designated regions as shown in Fig. $\underline{5}$.

The pressure and temperature profiles for atmospheric density, Rayleigh scattering, and ozone absorption cross section are provided by local ozonesonde or radiosonde measurement. Without a third wavelength, an iterative aerosol correction procedure [12] is applied to reduce errors arising from differential aerosol backscattering. This procedure substitutes the first estimated ozone from the signal term in Eq. (1) to derive the aerosol profile for the offline wavelength and iterates the aerosol and DIAL calculation until obtaining a stable solution. However, this procedure needs to assume a value for the Angström exponent and lidar ratio. These assumptions result in additional retrieval uncertainty.

\section{Ozone Measurements}

Figure 6 shows a lidar retrieval made on 30th June 2012 with a $10 \mathrm{~min}$ temporal integration $(18,000$ shots) and varying spatial resolution. The collocated ozonesonde retrieval at 13:10 local time and the Environmental Protection Agency (EPA) $(\sim 16 \mathrm{~km}$ away from lidar station) hourly surface measurements are shown as a comparison and a preliminary validation. The ozonesondes used in Huntsville 


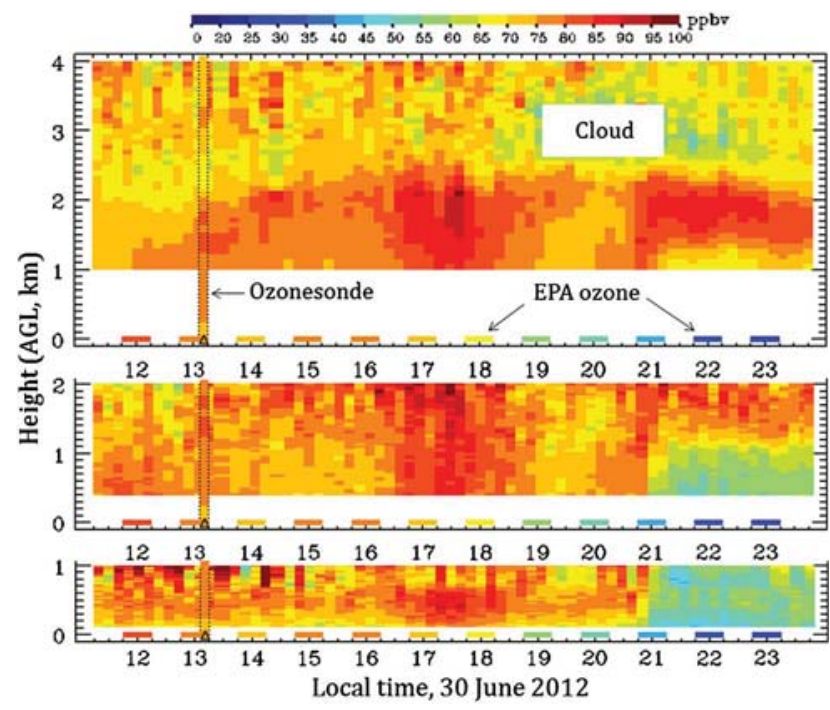

Fig. 6. Ozone lidar retrievals (channel 1-bottom, channel 2middle, and channel 3-top) compared with the ozonesonde (marked by the black triangle at 13:10 launch time) and EPA ( $\sim 16 \mathrm{~km}$ away) hourly surface measurements.

employ an electrochemical concentration cell sensor [34], with $2 \%$ unbuffered potassium iodide (KI) solution, to measure ozone with a vertical resolution of 100,150 $\mathrm{m}$ [35] and an accuracy better than $\pm 10 \%$ $[36,37]$. The ozone retrievals from three lidar channels (two independent receivers) are generally consistent with each other over their retrievable altitude ranges. All three channels' retrievals display the same ozone reduction below $1 \mathrm{~km}$ at 21:00 local time. The random noise in the DIAL retrievals increases with height due to the increasing statistical errors, which will be described in Section $\underline{6}$. The channel 1 daytime retrievals above $500 \mathrm{~m}$ appear noisier than nighttime and somewhat inconsistent with either channel 2 or the ozonesonde as a result of daytime solar background. The solar filter for channel 1 has somewhat lower out-of-band blocking. Channel 1 also has higher solar-to-signal ratios than the other two channels due to a larger FOV. However, this does not have a significant impact on the final joined retrievals because the altitude above $500 \mathrm{~m}$ is covered by channel 2 .

A large ozone gradient associated with a temperature inversion (not shown) on the ozonesonde profile suggests a mixed layer (ML) with top at $\sim 2.1 \mathrm{~km}$. The top of the ABL and its evolution can also be clearly seen on the lidar curtain plot (Fig. 6), indicating that the lidar has captured this important feature. Before 18:00, the EPA surface ozone varied between 70 and 80 ppbv with a peak at 12:00. After 18:00, the surface ozone decreased almost linearly to $\sim 20$ ppbv at midnight because of the development of a nocturnal (stable) boundary layer and nitrite titration of the ozone. The ozone evolution at higher altitudes differed from that observed at the surface. The upper-air ozone in the ML increased with time and peaked at $\sim 90 \mathrm{ppbv}$ several hours later between 17:00 and 18:00 due to mixing from the surface

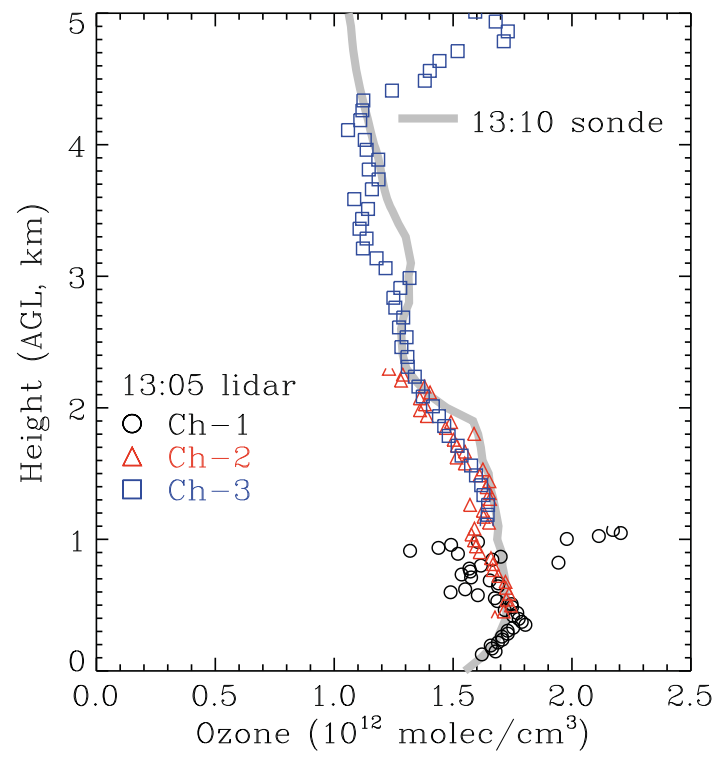

Fig. 7. Comparison of the 10 min DIAL retrievals for the three altitude/PMT channels and the collocated ozonesonde measurement. The mixed layer height is about $2.1 \mathrm{~km}$, suggested by a large ozone gradient and confirmed by a temperature inversion (not shown) from the ozonesonde profile.

and in situ production. Surface emissions are the principle pollution source typically observed in the summer daytime with little horizontal transport. However, it is not fully understood why the ozone aloft, originating at the surface, has a higher concentration than at the surface, although this phenomenon has been observed previously $[38,39]$. The ML ozone decreased $\sim 10 \mathrm{ppbv}$ between 20:00 and 21:00 mostly as a result of the decreasing photolysis rate caused by the intermittent cloud cover above the ABL [40]. After 21:00, the ozone below $1 \mathrm{~km}$ fell to $\sim 60 \mathrm{ppbv}$, while the upper ABL ozone remained at 80-90 ppbv, suggesting weak mixing in the residual layer.

Figure 7 provides a detailed comparison between the $10 \mathrm{~min}$ DIAL retrievals for all three channels at 13:05 and the ozonesonde measurement at 13:10. The ozone number densities on channels 1 and 2 are consistent in their overlapped region; however, they are $\sim 10 \%$ lower than the sonde at some heights. The channel 1 ozone retrievals agree with the sonde below $500 \mathrm{~m}$ and are slightly lower than the sonde above $500 \mathrm{~m}$. Slight adjustment of the SIB correction can correct the channel 1 retrievals at the upper range for this particular time. However, based on the whole lidar curtain in Fig. $\underline{6}$, those biases appear to be due to random noise originating with the uncharacterized solar background as mentioned previously. Interestingly, both the ozonesonde and lidar show a large ozone gradient (more obvious when displayed in units of mixing ratio) below $\sim 300 \mathrm{~m}$ in spite of a sunny summer midday. These measurements demonstrate that the upper-air ozone variations can be significantly different from the surface and the ML may not be well mixed. 


\section{Uncertainty Discussions}

Measurement uncertainties can be divided into random and systematic errors. The statistical uncertainty, arising from signal and background noise fluctuations, is the principal random error source determining measurement precision. Because of its importance, the statistical uncertainty has been extensively discussed in previous publications $[27,41,42]$. Generally, the statistical uncertainties increase with height due to the decaying SNR and become significant at the far range. With the assumption of a Poisson distribution governing PC, the statistical uncertainty is approximately proportional to $\left(\Delta r_{e}^{3} N A P_{L}\right)^{-1 / 2}[31,42]$, where $N$ represents the number of laser shots associated with the integrated time period, $A$ is the receiver area, and $P_{L}$ is the number of emitted laser photons. This means that an acceptable retrieval precision can be obtained by adjusting the spatial and temporal resolution. Figure 8 shows the modeled statistical uncertainties for our system with the vertical resolutions in Fig. 5 by using the averaged summer ozonesonde profile [43]. The statistical uncertainties are typically less than $4 \%$ within each channel's measurement range (Table 1).

Systematic errors are associated with (1) differential backscattering and extinction due to air molecules (Rayleigh scattering), aerosols, and other gases (e.g., $\mathrm{SO}_{2}, \mathrm{NO}_{2}$ ); (2) uncertainties in the ozone absorption cross section; and (3) instrumental uncertainties. The differential Rayleigh scattering results in an inaccuracy less than 1\% [5] using the pressure and temperature profile measured by local ozonesonde or radiosonde. The estimated error due to $\mathrm{SO}_{2}$ or $\mathrm{NO}_{2}$ for the 285-291 nm pair is minor, less than 1\% [12]. The aerosol impact can be reduced to a minor level for a two-wavelength lidar by coupling a Klett $[44,45]$ or Fernald [46] aerosol inversion algorithm $[\underline{5}, \overline{18}, \overline{47}]$ into the $\overline{\mathrm{DIA}} \mathrm{L}$ retrieval if the

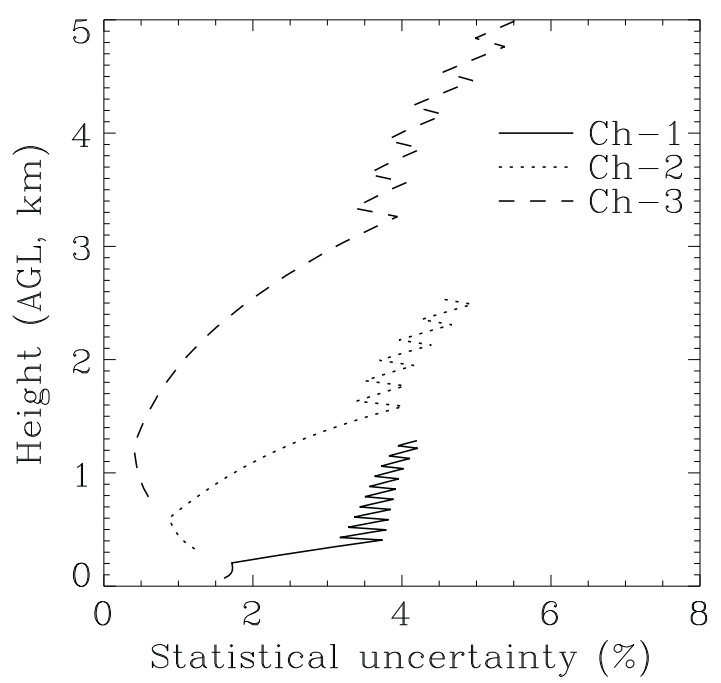

Fig. 8. Modeled statistical uncertainties for channels 1, 2, and 3 with the effective vertical resolutions shown in Fig. 5 by using an average summer ozonesonde profile.
Ångström exponent and lidar ratio are exactly known. The primary concern arises from the uncertainties in the assumed Angström exponent and lidar ratio, which have not been well characterized in the UV region (most data is at 308 and $355 \mathrm{~nm}$ ), and also the lack of local measurement to characterize aerosol types and their properties. Kuang et al. [12] have shown that the estimated errors due to aerosols in our lidar retrievals are within $\pm(5-20) \%$ depending on the accuracy of the Ångström exponent and lidar ratio.

Orphal [48] reviewed several current ozone crosssection data sets and found that they have an overall agreement to within 1\%-2\% after accounting for wavelength shifts, baseline effects, and spectral resolution. We choose to use the Brion-DaumontMalicet (BDM) ozone cross-section database [49-52] recommended by Liu et al. [53] for satellite retrievals from the UV measurements. The cross-section temperature dependence, changing slightly (within $2 \%$ ) for the Hartley band, is modeled by the quadratic polynomial fits from four temperatures 218, 228, 243, and $295 \mathrm{~K}$ [53]. Based on Orphal's [48] review, we believe the uncertainty in the differential ozone cross section is less than $2 \%$, translating into a DIAL retrieval uncertainty of a similar magnitude according to Eq. (1).

As shown by Fig. 4, the near-range lidar retrievals are sensitive to $r^{*}$. The retrieval uncertainty due to $r^{*}$ can be reduced to less than $1.5 \%$ above $125 \mathrm{~m}$ AGL through use of an oscilloscope with time measurement precision within $0.2 \mathrm{~ns}$. Moreover, this systematic error does not vary with atmospheric conditions or SNR, and thus can be calibrated against local ozone observations. We report retrievals only above the full overlap altitude for our ozone lidar and do not employ any partial overlap function. The SIB impact, varying largely with the near-range signal intensity, can be significant at the far ranges $(>3 \mathrm{~km})$. However, it can be reduced to $\pm 5 \%$ with empirical corrections.

The total root-mean-square error in the DIAL retrieval from all above sources is less than $10 \%$ excluding an extremely large-gradient aerosol condition. For checking the quality of the lidar retrievals, Fig. $\underline{9}$ presents the mean and $1-\sigma$ standard deviation of the 10 min lidar retrievals in Fig. $\underline{6}$ for each channel. It is natural that we always prefer the retrievals made by the channel with higher precision at the overlapped region. The ozone variability is associated with both the true atmospheric variations and the measurement uncertainties. The standard deviations are less than $10 \%$ below $4 \mathrm{~km}$ except for the larger deviations below $1 \mathrm{~km}$ mostly due to the ozone diurnal variations related to the $\mathrm{ABL}$ development suggested by Fig. 6 . This reasonable variability is consistent with the measurement uncertainty analysis.

It is worth noting that the retrieval errors due to aerosols are large near inhomogeneous layers, such as just above the surface and near the top of the ABL 


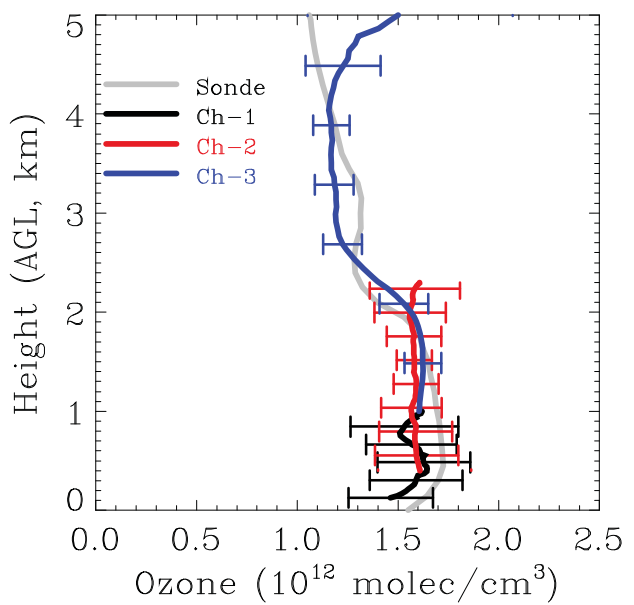

(a)

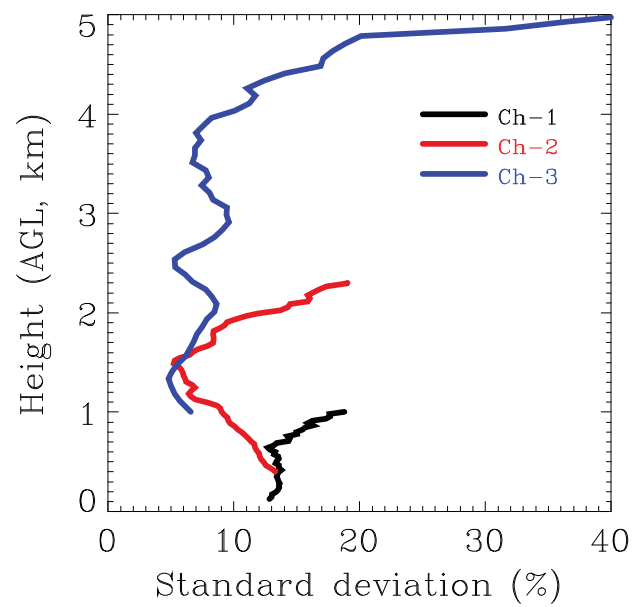

(b)

Fig. 9. Variability of the ozone lidar measurements in Fig. $\underline{6}$. (a) Average of the 10 min lidar profiles and the $1-\sigma$ standard deviation. (b) The $1-\sigma$ standard deviation in units of percentage.

where the statistical uncertainties are relatively small for the ground-based system. Based on the above analysis and the comparison of the retrievals and the ozonesonde observation, the estimated total measurement precision for altitudes up to $4 \mathrm{~km}$ AGL is about $\pm 10 \%$ under normal aerosol conditions and could be up to $\pm 20 \%$ under an extremely turbid sky condition. This conclusion is consistent with Figs. 7 and 9 , which show that the retrievals from the different channels agree within $\pm 5 \%$ and the lidar agrees with the ozonesonde within $\pm 10 \%$.

\section{Conclusions}

Previous ground-based ozone lidars that were not operating in a scanning configuration were unable to consistently measure ozone below $\sim 500 \mathrm{~m}$ AGL. By adding a $2.5 \mathrm{~cm}$ receiver to the previous system [12], we have expanded the ozone measurements down to $125 \mathrm{~m}$ AGL and significantly reduce the observational gap between the surface and upperaltitude air. We have presented a hardware design, signal processing and retrieval techniques, error analysis, and a preliminary validation result for ground-based ozone lidar measurements within the ABL.

Using two receivers and three PMT (altitude) channels, the UAHuntsville lidar measures ABL ozone with a typical temporal resolution of $10 \mathrm{~min}$ and spatial resolutions ranging from $\sim 150$ to $550 \mathrm{~m}$. A careful experiment to minimize the range offset $\left(r^{*}\right)$ between the on- and off-line wavelength is critical for measuring the near-ground ozone. After the proper calibration of $r^{*}$, the lidar was able to monitor ozone up to $4 \mathrm{~km}$ AGL with errors typically within $\pm 10 \%$, suggested by both the analysis and the collocated ozonesonde measurement.

The lidar measurements in Fig. $\underline{6}$ present a nice example of the ABL ozone variations affected by the surface emissions and the diurnal variation of the ABL structures. The distinct evolutions of the surface and upper-air ozone demonstrate the importance of the high-resolution ABL ozone profiling, particularly for air-quality models.

The authors thank Tom McGee of NASA/GSFC, Stuart McDermid, and Thierry Leblanc of NASA/ JPL for extensive discussions about lidar instrumentation, Jack Kaye and Jay Al-Saadi of NASA/ headquarters for continuing support, Wesley Cantrell and Guanyu Huang of UAHuntsville for providing the ozonesonde data, and Debra Hopson of the Huntsville Department of Natural Resources and Environmental Management for providing the surface ozone data. This work was supported by NASA's Science Mission Directorate and NOAA's National Environmental Satellite, Data, and Information Service (NESDIS). The UAHuntsville ozone lidar is affiliated with the Tropospheric Ozone Lidar NETwork (TOLNET) and the Network for Detection of Atmospheric Composition Change (NDACC).

\section{References}

1. R. M. Banta, C. J. Senff, A. B. White, M. Trainer, R. T. McNider, R. J. Valente, S. D. Mayor, R. J. Alvarez, R. M. Hardesty, D. Parrish, and F. C. Fehsenfeld, "Daytime buildup and nighttime transport of urban ozone in the boundary layer during a stagnation episode," J. Geophys. Res. 103, 22519-22544 (1998).

2. P. Solomon, E. Cowling, G. Hidy, and C. Furiness, "Comparison of scientific findings from major ozone field studies in North America and Europe," Atmos. Environ. 34, 1885-1920 (2000).

3. Q. Li, D. J. Jacob, I. Bey, P. I. Palmer, B. N. Duncan, B. D. Field, R. V. Martin, A. M. Fiore, R. M. Yantosca, D. D. Parrish, P. G. Simmonds, and S. J. Oltmans, "Transatlantic transport of pollution and its effects on surface ozone in Europe and North America," J. Geophys. Res. 107, ACH 4-1-ACH 4-21 (2002).

4. E. V. Browell, M. A. Fenn, C. F. Butler, W. B. Grant, R. C. Harriss, and M. C. Shipham, "Ozone and aerosol distributions in the summertime troposphere over Canada," J. Geophys. Res. 99, 1739-1755 (1994).

5. R. J. Alvarez, C. J. Senff, A. O. Langford, A. M. Weickmann, D. C. Law, J. L. Machol, D. A. Merritt, R. D. Marchbanks, S. P. Sandberg, W. A. Brewer, R. M. Hardesty, and R. M. Banta, "Development and application of a compact, tunable, solidstate airborne ozone lidar system for boundary layer profiling," J. Atmos. Ocean. Technol. 28, 1258-1272 (2011). 
6. A. O. Langford, C. J. Senff, R. J. Alvarez, R. M. Banta, R. M. Hardesty, D. D. Parrish, and T. B. Ryerson, "Comparison between the TOPAZ airborne ozone lidar and in situ measurements during TexAQS 2006," J. Atmos. Ocean. Technol. 28, 1243-1257 (2011).

7. J. A. Sunesson, A. Apituley, and D. P. J. Swart, "Differential absorption lidar system for routine monitoring of tropospheric ozone," Appl. Opt. 33, 7045-7058 (1994).

8. Y. Zhao, R. D. Marchbanks, and R. M. Hardesty, "ETL's transportable lower-troposphere ozone lidar and its applications in air-quality studies," Proc. SPIE 3127, 53-62 (1997).

9. S. C. Choi, Y.-J. Kim, D. H. Kim, H. K. Cha, D.-K. Ko, and J. Lee, "A differential absorption lidar (DIAL) for ozone measurements in the planetary boundary layer in an urban area," J. Korean Phys. Soc. 44, 1432-1437 (2004).

10. J. Machol, R. Marchbanks, C. Senff, B. McCarty, W. Eberhard, W. Brewer, R. Richter, R. Alvarez II, D. Law, A. Weickmann, and S. Sandberg, "Scanning tropospheric ozone and aerosol lidar with double-gated photomultipliers," Appl. Opt. 48, 512-524 (2009)

11. M. Bristow, D. Bundy, and A. Wright, "Signal linearity, gain stability, and gating in photomultipliers: application to differential absorption lidars," Appl. Opt. 34, 4437-4452 (1995).

12. S. Kuang, J. F. Burris, M. J. Newchurch, S. Johnson, and S. Long, "Differential absorption lidar to measure subhourly variation of tropospheric ozone profiles," IEEE Trans. Geosci. Remote Sens. 49, 557-571 (2011).

13. I. McDermid, G. Beyerle, D. Haner, and T. Leblanc, "Redesign and improved performance of the tropospheric ozone lidar at the jet propulsion laboratory table mountain facility," Appl. Opt. 41, 7550-7555 (2002).

14. E. V. Browell, S. Ismail, and S. T. Shipley, "Ultraviolet DIAL measurements of $\mathrm{O}_{3}$ profiles in regions of spatially inhomogeneous aerosols," Appl. Opt. 24, 2827-2836 (1985).

15. M. H. Proffitt and A. O. Langford, "Ground-based differential absorption lidar system for day or night measurements of ozone throughout the free troposphere," Appl. Opt. 36, 2568-2585 (1997).

16. K. A. Elsayed, S. S. Chen, L. B. Petway, B. L. Meadows, W. D. Marsh, W. C. Edwards, J. C. Barnes, and R. J. DeYoung, "Highenergy, efficient, $30 \mathrm{~Hz}$ ultraviolet laser sources for airborne ozone-lidar systems," Appl. Opt. 41, 2734-2739 (2002).

17. V. Kovalev and J. McElroy, "Differential absorption lidar measurement of vertical ozone profiles in the troposphere that contains aerosol layers with strong backscattering gradients: a simplified version," Appl. Opt. 33, 8393-8401 (1994).

18. F. Immler, "A new algorithm for simultaneous ozone and aerosol retrieval from tropospheric DIAL measurements," Appl. Phys. B 76, 593-596 (2003).

19. H. Eisele and T. Trickl, "Improvements of the aerosol algorithm in ozone lidar data processing by use of evolutionary strategies," Appl. Opt. 44, 2638-2651 (2005).

20. S. Kuang, M. J. Newchurch, J. burris, L. Wang, P. Buckley, S. Johnson, K. Knupp, G. Huang, and D. Phillips, "Nocturnal ozone enhancement in the lower troposphere observed by lidar," Atmos. Environ. 45, 6078-6084 (2011).

21. S. Kuang, M. J. Newchurch, J. Burris, L. Wang, K. Knupp, and G. Huang, "Stratosphere-to-troposphere transport revealed by ground-based lidar and ozonesonde at a midlatitude site," J. Geophys. Res. 117, D18305 (2012).

22. J. Burris, T. McGee, W. Hoegy, P. Newman, L. Lait, L. Twigg, G. Sumnicht, W. Heaps, C. Hostetler, R. Neuber, and K. F. Künzi, "Lidar temperature measurements during the SOLVE campaign and the absence of polar stratospheric clouds from regions of very cold air," J. Geophys. Res. 107, 8297 (2002).

23. NOAA, U. S. Standard Atmosphere, 1976 (Government Printing Office, 1976).

24. D. P. Donovan, J. A. Whiteway, and A. I. Carswell, "Correction for nonlinear photon-counting effects in lidar systems," Appl. Opt. 32, 6742-6753 (1993).

25. R. Newsom, D. Turner, B. Mielke, M. Clayton, R. Ferrare, and C. Sivaraman, "Simultaneous analog and photon counting detection for Raman lidar," Appl. Opt. 48, 3903-3914 (2009).

26. F. Cairo, F. Congeduti, M. Poli, S. Centurioni, and G. Di Donfrancesco, "A survey of the signal-induced noise in photomultiplier detection of wide dynamics luminous signals," Rev. Sci. Instrum. 67, 3274-3280 (1996).

27. G. J. Megie, G. Ancellet, and J. Pelon, "Lidar measurements of ozone vertical profiles," Appl. Opt. 24, 3454-3463 (1985).

28. A. Savitzky and M. J. E. Golay, "Smoothing and differentiation of data by simplified least squares procedures," Anal. Chem. 36, 1627-1639 (1964).

29. S. Godin-Beekmann, J. Porteneuve, and A. Garnier, "Systematic DIAL lidar monitoring of the stratospheric ozone vertical distribution at observatoire de haute-provence $\left(43.92^{\circ} \mathrm{N}\right.$, $\left.5.71^{\circ} \mathrm{E}\right), "$ J. Environ. Monit. 5, 57-67 (2003).

30. R. W. Schafer, "What is a Savitzky-Golay filter? [lecture notes]," IEEE Signal Process. Mag. 28(4), 111-117 (2011).

31. S. Godin, A. Carswell, D. Donovan, H. Claude, W. Steinbrecht, I. McDermid, T. McGee, M. Gross, H. Nakane, D. Swart, H. Bergwerff, O. Uchino, P. von der Gathen, and R. Neuber, "Ozone differential absorption lidar algorithm intercomparison," Appl. Opt. 38, 6225-6236 (1999).

32. G. Pappalardo, A. Amodeo, M. Pandolfi, U. Wandinger, A. Ansmann, J. Bsenberg, V. Matthias, V. Amiridis, F. De Tomasi, M. Frioud, M. Iarlori, L. Komguem, A. Papayannis, F. Rocadenbosch, and X. Wang, "Aerosol lidar intercomparison in the framework of the EARLINET project. 3. Raman lidar algorithm for aerosol extinction, backscatter, and lidar ratio," Appl. Opt. 43, 5370-5385 (2004).

33. G. Beyerle and I. McDermid, "Altitude range resolution of differential absorption lidar ozone profiles," Appl. Opt. 38, 924-927 (1999).

34. W. D. Komhyr, "Electrochemical cells for gas analysis," Ann. Geophys. 25, 203-210 (1969).

35. W. D. Komhyr, R. A. Barnes, G. B. Brothers, J. A. Lanthrop, and D. P. Opperman, "Electrochemical concentration cell ozonesonde performance evaluation during STOIC 1989," J. Geophys. Res. 100, 9231-9244 (1995).

36. H. G. J. Smit, W. Straeter, B. J. Johnson, S. J. Oltmans, J. Davies, D. W. Tarasick, B. Hoegger, R. Stubi, F. J. Schmidlin, T. Northam, A. M. Thompson, J. C. Witte, I. Boyd, and F. Posny, "Assessment of the performance of ECC-ozonesondes under quasi-flight conditions in the environmental simulation chamber: insights from the Juelich ozone sonde intercomparison experiment (JOSIE)," J. Geophys. Res. 112, D19306 (2007).

37. B. J. Johnson, D. Helmig, and S. Oltmans, "Evaluation of ozone measurements from a tethered balloon-sampling platform at South Pole station in December 2003," Atmos. Environ. 42, 2780-2787 (2008).

38. C. M. Berkowitz, T. Jobson, G. Jiang, C. W. Spicer, and P. V. Doskey, "Chemical and meteorological characteristics associated with rapid increases of $\mathrm{O}_{3}$ in Houston, Texas," J. Geophys. Res. 109, D10307 (2004).

39. R. M. Banta, C. J. Senff, R. J. Alvarez, A. O. Langford, D. D. Parrish, M. K. Trainer, L. S. Darby, R. M. Hardesty, B. Lambeth, J. A. Neuman, W. M. Angevine, J. NielsenGammon, S. P. Sandberg, and A. B. White, "Dependence of daily peak $\mathrm{O}_{3}$ concentrations near Houston, Texas on environmental factors: wind speed, temperature, and boundary-layer depth," Atmos. Environ. 45, 162-173 (2011).

40. A. Pour-Biazar, R. T. McNider, S. J. Roselle, R. Suggs, G. Jedlovec, D. W. Byun, S. Kim, C. J. Lin, T. C. Ho, S. Haines, B. Dornblaser, and R. Cameron, "Correcting photolysis rates on the basis of satellite observed clouds," J. Geophys. Res. 112, D10302 (2007).

41. M. R. Measures, Laser Remote Sensing: Fundamentals and Applications (Wiley, 1984).

42. A. Papayannis, G. Ancellet, J. Pelon, and G. Mègie, "Multiwavelength lidar for ozone measurements in the troposphere and the lower stratosphere," Appl. Opt. 29, 467-476 (1990).

43. M. J. Newchurch, M. A. Ayoub, S. Oltmans, B. Johnson, and F. J. Schmidlin, "Vertical distribution of ozone at four sites in the United States," J. Geophys. Res. 108, 4031 (2003).

44. J. D. Klett, "Stable analytical inversion solution for processing lidar returns," Appl. Opt. 20, 211-220 (1981). 
45. J. D. Klett, "Lidar inversion with variable backscatter/ extinction ratios," Appl. Opt. 24, 1638-1643 (1985).

46. F. Fernald, "Analysis of atmospheric lidar observations: some comments," Appl. Opt. 23, 652-653 (1984).

47. O. Uchino and I. Tabata, "Mobile lidar for simultaneous measurements of ozone, aerosols, and temperature in the stratosphere," Appl. Opt. 30, 2005-2012 (1991).

48. J. Orphal, "A critical review of the absorption cross-sections of $\mathrm{O}_{3}$ and $\mathrm{NO}_{2}$ in the 240-790 nm region," J. Photochem. Photobiol. A 157, 185-209 (2003).

49. D. Daumont, J. Brion, J. Charbonnier, and J. Malicet, "Ozone UV spectroscopy I: absorption cross-sections at room temperature," J. Atmos. Chem. 15, 145-155 (1992).

50. J. Brion, A. Chakir, D. Daumont, and J. Malicet, "Highresolution laboratory absorption cross section of $\mathrm{O} 3$ temperature effect," Chem. Phys. Lett. 213, 610-612 (1993).

51. C. Malicet, D. Daumont, J. Charbonnier, C. Parisse, A. Chakir and J. Brion, "Ozone UV spectroscopy, II. Absorption crosssections and temperature dependence," J. Atmos. Chem. 21, 263-273 (1995).

52. J. Brion, A. Chakir, J. Charbonnier, D. Daumont, C. Parisse, and J. Malicet, "Absorption spectra measurements for the ozone molecule in the 350-830 nm region," J. Atmos. Chem. 30, 291-299 (1998).

53. X. Liu, K. Chance, C. E. Sioris, and T. P. Kurosu, "Impact of using different ozone cross sections on ozone profile retrievals from global ozone monitoring experiment (GOME) ultraviolet measurements," Atmos. Chem. Phys. 7, 3571-3578 (2007). 